\title{
THỰC TRANG KỸ NĂNG GIAO TIẾP, ỨNG XỬ CỦA KỸ THUÂTT VIÊN TẠI BỆNH VIỆN TRƯỜNG ĐẠI HỌC KỸ THUẬT Y TẾ HẢI DƯƠNG
}

\author{
Lê Thị Thanh Trà*, Lê Văn Thêm*, Nguyễn Thị Nhung*
}

TÓM TẮT

Mục tiêu: Mô tả kỹ năng giao tiếp, ứng xử của kỹ thuật viên của kỹ thuât viên tại Bênh viện Trường Đại học Kỹ thuật $Y$ tế Hải Dương năm 2017. Phương pháp: Nghiền cứu ngang có phân tích trên 26 kỹ thuật viên đang công tác tại Bệnh viện Trường Đại hoc Kỹ thuật $Y$ tế Hải Dương. Kểt quả: Kỹ thuật viên có độ tuổi từ 21 đến 30 tuổi chiếm tỷ lệ đa số $80.8 \%$, tỷ lệ về giới không có sự chênh lệnh nhiều (Nam giới chiểm $46.2 \%$, nữ giới chiếm $53.8 \%$ ) trình độ của kỹ thuật viên chủ yếu là trình độ đại học chiếm $84 \% \%$, thâm niên công tác từ 5 năm - 10 năm chiếm tỷ lế cao nhất $57.7 \%$. Kỹ thuật viên có kỹ năng giao tiếp tốt chiếm $80.8 \%$. Bên canh đó, kỹ năng đăt câu hỏi và phản hồi còn $19.2 \%$ là chưa tốt. Kết luận: $80,8 \%$ các tiêu chí về kỹ năng giao tiếp, ứng xử của kỹ thuật viên được đánh giá tốt

\section{SUMMARY}

CURRENT SITUATION OF MEDICAL TECHNICIANS' COMMUNICATION SKILLS AT HAI DUONG MEDICAL TECHNICAL UNIVERSITY IN 2017

Objectives: To describe the communication and behavioral skills of medical technicians at Hai Duong Medical Technology University Hospital in 2017. Methods: Horizontal study among over 26 medical technicians working at Hai Duong Medical Technical University. Results: the number of medical technicians aged from 21 to 30 years old accounted for the majority of $80.8 \%$, the gender ratio does not have much difference $(46.2 \%$ of men, $53.8 \%$ of women). The technicians who have university degree accounted for $84 \% \%$, working seniority from 5 years to10 years accounted for the highest rate $57.7 \%$. The ratio of the technician who have goo skills accounted for $80.8 \%$. Besides, the questioning and feedback skills of $19.2 \%$ are not good. Conclusion: $80,8 \%$ of the criteria for technicians' communication and behavioral skills are well assessed.

\section{I. ĐẶT VẤN ĐỀ}

Chất lượng chăm sóc y tế đang được cả xã hội quan tâm và chú ý. Chất lượng chăm sóc y tế không chỉ phụ thuộc vào máy móc, trang thiết bị mà còn liên quan chặt chẽ tới quy trình chăm sóc cũng như kỹ năng tay nghề và tinh thần, thái độ phục vụ của cán bộ y tế.

*Trường đại hoc kỹ thuât Y tế Hải Dương Chịu trách nhiệm chính: Lê Thị Thanh Trà Email: traltt@hmtu.edu.vn

Ngày nhận bài: 4.01.2021

Ngày phản biên khoa học: 24.2.2021

Ngày duyệt bài: 9.3.2021
Đổi mới phong cách, thái độ phục vụ của cán bộ y tế hướng tới sự hài lòng của người bệnh được ngành $Y$ tế xác định là một trong nhửng nhiệm vụ quan trọng nhằm củng cố niềm tin và sự hài lòng của người bệnh và gia đình người bệnh, là yếu tố quan trọng để nâng cao chất lượng dịch vụ y tế, đẩy mạnh công tác chăm sóc và bảo vê sức khỏe cho người dân [7]. Để cải thiện chỉ số hài lòng của người bệnh, khâu giao tiếp trong bệnh viện là yếu tố quan trọng, góp phần làm cho người bênh yên tâm, hợp tác điều trị và trong nhiều trường hợp, nó còn quyết định sự thành công trong việc chữa bệnh cho người bệnh.

Nâng cao kỹ năng giao tiếp, ứng xử của cán bộ y tế tại các cơ sở khám chưa bệnh hiện là đang được ngành y tế cũng như toàn xã hội đặc biệt chú trọng. Hiện nay, Bệnh viện Trường Đại học Kỹ thuật $Y$ tế Hải Dương cùng với việc mở rộng phạm vi hoạt động, nâng cao chất lượng dịch vụ khám chữa bệnh, bệnh viện cũng đặc biệt quan tâm đến cải thiện kỹ năng giao tiếp, ứng xử của cán bộ y tế. Để có cơ sở khoa học giúp lãnh đạo Bệnh viện và cán bộ y tế có kế hoạch cụ thể trong việc cải thiện kỹ năng giao tiếp, ứng xử từ đó góp phần nâng cao chất lượng khám chữa bệnh, nâng cao uy tín, thương hiều của Bênh viện.

Xuất phát từ vấn đề nêu trên chúng tôi tiến hành nghiên cứu này với mục tiêu: Mô tả $k \tilde{y}$ năng giao tiếp, ứng xử của ki் thuật viên của kỹ thuật viên tại Bệnh viện Trường Đại học Kỹ thuật $Y$ tế Hải Dướng.

II. ĐỐI TƯợNG VÀ PHƯƠNG PHÁP NGHIÊN CỨU

2.1. Đối tượng nghiên cứu. Kỹ thuật viên làm việc bệnh tại Bệnh viện Trường Đại học Kỹ thuật Y tế Hải Dương năm 2017

Tiêu chuẩn lựa chọn: Đồng ý tham gia nghiên cứu

Tiêu chuẩn loai trừ: Những cán bộ y tế từ chối tham gia nghiển cứu.

2.2. Phương pháp nghiên cứu

- Thiết kế nghiên cứu: Nghiên cứu ngang

- Cỡ mẫu, chọn mẫu: Toàn bộ 26 kỹ thuật viên đang làm tại Bệnh viện Trường Đại học Kỹ thuật Y tế Hải Dương

- Phương pháp thu thập số liệu

Quan sát trực tiếp (có tham dự) đối với kỹ thuật viên dựa trên bảng kiểm đánh giá kỹ năng 
giao tiếp của Bộ y tế ban hành trong cuốn tài liệu "Hướng dẫn giao tiếp ứng xử của cán bộ y tế" năm 2015

+ Số lần quan sát: Mỗi đối tượng nghiên cứu quan sát 1 lần.

+ Thời điểm quan sát:

Quan sát kỹ thuật viên hướng dẫn 1 bệnh nhân vào buổi sáng trong giờ hành chính.

- Đánh giá kết quả giao tiếp:

Bộ bảng kiểm mỗi tiêu chuẩn gồm 10 câu hỏi đánh giá bằng 4 mức độ:

Quy định:

Không làm $=0$ điểm

Làm không đầy đủ $=1$ điểm

Làm được nhưng chưa thành thạo $=2$ điểm

Làm tốt, thành thạo $=3$ điểm

Biến tổ hợp được xem là "Tốt" khi tổng điểm từng kỹ năng đạt từ 22 điểm trở lên, dưới 22 điểm = "chưa tốt". Kỹ năng giao tiếp ứng xử của cán bộ y tế tại bệnh viện được đánh giá là "tốt" khi 3 kỹ năng: Kỹ năng nói và kỹ năng lắng nghe, Kỹ năng đặt câu hỏi và phản hồi, Kỹ năng giao tiếp không lời, được đánh giá là "tốt", "chưa tốt" khi một trong ba kỹ năng trên đánh giá "chưa tốt".

- Phương pháp phân tích và xử lý số liệu: Bằng phần mềm SPSS 16.0

III. KẾT QUẢ NGHIÊN CỨU

Bảng 3.1. Độ tuổi của đôi tượng nghiên Cứu

\begin{tabular}{|c|c|c|}
\hline Độ tuối & Số lượng & Tỷ lệ \% \\
\hline $21-30$ tuối & 21 & 80.8 \\
\hline $31-40$ tuối & 5 & 19.2 \\
\hline Tồng & $\mathbf{2 6}$ & $\mathbf{1 0 0}$ \\
\hline
\end{tabular}

Nhận xét: Qua bảng 1 cho thấy đội ngũ kỹ thuật viên có độ tuổi từ 21 đến 30 tuổi chiếm tỳ lệ đa số $80.8 \%$

\section{Bảng 3.6: Kỹ năng nói và lắng nghe}

\begin{tabular}{|c|c|c|c|c|c|c|c|c|}
\hline \multirow[t]{2}{*}{ Kỹ năng nói và lắng nghe } & \multicolumn{2}{|c|}{ Không làm } & \multicolumn{2}{|c|}{$\begin{array}{l}\text { Làm không } \\
\text { đây đủ }\end{array}$} & \multicolumn{2}{|c|}{$\begin{array}{l}\text { Làm được } \\
\text { nhưng chưa } \\
\text { thành thạo }\end{array}$} & \multicolumn{2}{|c|}{$\begin{array}{l}\text { Làm tốt, } \\
\text { thành thạo }\end{array}$} \\
\hline & $\mathbf{n}$ & Tỷ lệ \% & $\mathbf{n}$ & $\begin{array}{c}\text { Tỷ lệ } \\
\%\end{array}$ & $\mathbf{n}$ & Tỷ lệ \% & $\mathbf{n}$ & $\begin{array}{l}\text { Tỷ lệ } \\
\%\end{array}$ \\
\hline $\begin{array}{l}\text { Chào và hỏi tên người bệnh, giới thiệu } \\
\text { tên CBYT, thể hiện sự tôn trọng, thân } \\
\text { thiện với NB. }\end{array}$ & 0 & 0 & 0 & 0 & 25 & 96.2 & 1 & 3.8 \\
\hline Cách xưng hô thích hợp với người bệnh & 0 & 0 & 0 & 0 & 4 & 15.4 & 22 & 84.6 \\
\hline $\begin{array}{l}\text { Nói chính xác, rõ ràng, đầy đủ và lo - } \\
\text { gic. }\end{array}$ & 0 & 0 & 0 & 0 & 2 & 7.7 & 24 & 92.3 \\
\hline Tốc độ nói, âm lượng vừa đủ & 0 & 0 & 0 & 0 & 2 & 7.7 & 24 & 92.3 \\
\hline $\begin{array}{l}\text { Nói tập trung vào chủ đề chính, nhấn } \\
\text { mạnh điểm quan trọng. }\end{array}$ & 0 & 0 & 0 & 0 & 2 & 7.7 & 24 & 92.3 \\
\hline Sử dụng từ ngữ phù hợp. & 0 & 0 & 0 & 0 & 3 & 11.5 & 23 & 88.5 \\
\hline
\end{tabular}

Bảng 3.2. Giới tính của đôi tượng nghiên Cúu

\begin{tabular}{|c|c|c|}
\hline Giới tính & Số lượng & Tỷ lệ \% \\
\hline Nam & 12 & 46.2 \\
\hline Nữ & 14 & 53.8 \\
\hline Tống & $\mathbf{2 6}$ & $\mathbf{1 0 0}$ \\
\hline
\end{tabular}

Nhận xét: Qua bảng 3.2 cho thấy tỷ lệ kỹ thuật viên là nam chiếm $46.2 \%$, nữ giới chiếm $53.8 \%$.

Bảng 3.3. Trình độ của đôî tượng nghiên cứu

\begin{tabular}{|c|c|c|}
\hline Trình độ & Số lượng & Tỷ lệ \% \\
\hline Đại học & 21 & 80.8 \\
\hline Cao đắng & 1 & 3.8 \\
\hline Trung cấp & 4 & 15.4 \\
\hline Tống & $\mathbf{2 6}$ & $\mathbf{1 0 0}$ \\
\hline
\end{tabular}

Nhân xét: Trình độ của kỹ thuật viên chủ yếu là trình độ đại học chiếm $80.8 \%$

Bảng 3.4. Thâm niên công tác của đối tượng nghiên cứlu

\begin{tabular}{|c|c|c|}
\hline Thâm niên & Số lượng & Tỷ lệ $\%$ \\
\hline$<5$ năm & 9 & 34.6 \\
\hline 5 đến 10 năm & 15 & 57.7 \\
\hline Trên 10 năm & 2 & 7.7 \\
\hline Tống & $\mathbf{2 6}$ & $\mathbf{1 0 0}$ \\
\hline
\end{tabular}

Nhận xét: Tại bệnh viện kỹ thuật viên có thâm niên công tác từ 5 năm - 10 năm chiếm tỷ lệ cao nhất $57.7 \%$.

Bảng 3.5. Tổng thu nhập của đôî tượng nghiên cứu

\begin{tabular}{|c|c|c|}
\hline Tống thu nhập & Số lượng & Tỷ lệ \% \\
\hline$<5$ triệu & 0 & 0 \\
\hline Tữ 5 đến 10 triệu & 26 & 100 \\
\hline Trên 10 triệu & 0 & 0 \\
\hline Tống & $\mathbf{2 6}$ & $\mathbf{1 0 0}$ \\
\hline
\end{tabular}

Nhân xét: $100 \%$ kỹ thuật viên làm việc tại bệnh viện có thu nhập từ 5 triệu đến 10 triệu. 


\begin{tabular}{|c|c|c|c|c|c|c|c|c|}
\hline Thế hiện sự lắng nghe. & 0 & 0 & 0 & 0 & 5 & 19.2 & 21 & 80.8 \\
\hline $\begin{array}{c}\text { Không làm việc khác khi đang lắng } \\
\text { nghe. }\end{array}$ & 0 & 0 & 0 & 0 & 5 & 19.2 & 21 & 80.8 \\
\hline Không đột ngột ngắt lời người bệnh & 0 & 0 & 0 & 0 & 2 & 7.7 & 24 & 92.3 \\
\hline $\begin{array}{c}\text { Kết hợp sử dụng ngôn ngữ không lời } \\
\text { phù hợp, chào và cám ơn người bệnh } \\
\text { khi kết thúc. }\end{array}$ & 0 & 0 & 0 & 0 & 24 & 92.3 & 2 & 7.7 \\
\hline
\end{tabular}

Nhận xét: Qua bảng cho thấy kỹ năng nói và lắng nghe của kỹ thuât viên được đánh giá chủ yếu là làm tốt và thành thạo $(80,8-92,3 \%)$. Tiêu chí chào và hỏi tên người bệnh, giới thiệu tên $C B Y T$, thể hiện sự tôn trọng, thân thiện với NB kỹ thuật viên làm được nhưng chưa thành thạo chiếm $96.2 \%$, làm tốt, thành thạo chiếm $3.8 \%$ và kêt hợp sử dụng ngôn ngữ không lời phù hợp, chào và cảm ơn người bệnh khi kết thúc kỹ thuật viên làm được nhưng chưa thành thạo chiếm $92.3 \%$; làm tốt, thành thạo chiếm 7,7\%.

Bảng 3.7: Kỹ năng đặt câu hỏi và phản hồi

\begin{tabular}{|c|c|c|c|c|c|c|c|c|}
\hline \multirow[t]{2}{*}{ Kỹ năng đặt câu hỏi và phản hồi } & \multicolumn{2}{|c|}{ Không làm } & \multicolumn{2}{|c|}{$\begin{array}{l}\text { Làm } \\
\text { không đây } \\
\text { đủ }\end{array}$} & \multicolumn{2}{|c|}{$\begin{array}{l}\text { Làm được } \\
\text { nhưng chưa } \\
\text { thành thạo }\end{array}$} & \multicolumn{2}{|c|}{$\begin{array}{l}\text { Làm tốt, } \\
\text { thành thạo }\end{array}$} \\
\hline & $\mathbf{n}$ & $\begin{array}{c}\text { Tỷ lệ } \\
\text { \% }\end{array}$ & $n$ & $\begin{array}{l}\text { Tỷ lệ } \\
\%\end{array}$ & $\mathrm{n}$ & $\begin{array}{l}\text { Tỳ lệ } \\
\%\end{array}$ & $\mathbf{n}$ & $\begin{array}{l}\text { Tỷ lệ } \\
\%\end{array}$ \\
\hline $\begin{array}{c}\text { Chào và hỏi tên người bệnh, giới } \\
\text { thiệu tên CBYT, giải thích mục đích } \\
\text { cuộc giao tiếp }\end{array}$ & 0 & 0 & 1 & 3.8 & 24 & 92.3 & 1 & 3.8 \\
\hline $\begin{array}{c}\text { Hỏi từng câu một } \\
\text { Đặt câu hỏi ngắn gọn, rõ nghĩa }\end{array}$ & 0 & 0 & 0 & 0 & 4 & 15.4 & 22 & 84.6 \\
\hline $\begin{array}{l}\text { Câu hỏi phải dể hiểu và phù hợp với } \\
\text { trình độ hiểu biết của người bệnh }\end{array}$ & 0 & 0 & 0 & 0 & 2 & 7.7 & 24 & 92.3 \\
\hline $\begin{array}{l}\text { Đặt các câu hỏi đóng, mở, gợi ý phù } \\
\text { hợp với mục đích cần hỏi }\end{array}$ & 0 & 0 & 3 & 11.5 & 4 & 15.4 & 19 & 73.1 \\
\hline $\begin{array}{c}\text { Sau khi hỏi phải dành thời gian cho } \\
\text { người bệnh trả lời }\end{array}$ & 1 & 3.8 & 0 & 0 & 4 & 15.4 & 21 & 80.8 \\
\hline $\begin{array}{l}\text { CBYT tóm tắt laai những thông tin } \\
\text { mà người bệnh vừa cung cấp }\end{array}$ & 3 & 11.5 & 1 & 3.8 & 2 & 7.7 & 20 & 76.9 \\
\hline CBYT đưa ra ý kiến của mình & 4 & 15.4 & 1 & 3.8 & 4 & 15.4 & 17 & 65.4 \\
\hline $\begin{array}{l}\text { CBYT kiểm tra laai nhận thức của } \\
\text { người bệnh }\end{array}$ & 3 & 11.5 & & & 5 & 19.2 & 18 & 69.2 \\
\hline $\begin{array}{c}\text { CBYT trả lời những câu hỏi của } \\
\text { người bệnh }\end{array}$ & 1 & 3.8 & 1 & 3.8 & 6 & 23.1 & 18 & 69.2 \\
\hline $\begin{array}{l}\text { Kết hợp sử dụng ngôn ngữ không lời } \\
\text { phù hợp. Chào và cảm ơn người } \\
\text { bệnh khi kết thúc }\end{array}$ & 0 & 0 & 0 & 0 & 24 & 92.3 & 2 & 7.7 \\
\hline
\end{tabular}

Nhận xét: Kết quả cho thấy kỹ năng đặt câu hỏi và phản hồi của kỹ thuật viên phần lớn làm tốt và thành thạo $(65,4-92,3 \%)$. Tuy nhiên, theo quan sát vẫn còn $11.5 \%$ kỹ thuật viên không tóm tắt lại những thông tin mà người bệnh vừa cung cấp, $15.4 \%$ kỹ thuật viên đưa ra ý kiến của mình.

Bảng 3.8: Kỹ năng giao tiếp không lời

\begin{tabular}{|c|c|c|c|c|c|c|c|c|}
\hline \multirow{2}{*}{ Kỹ năng giao tiếp không lời } & \multicolumn{2}{|c|}{$\begin{array}{l}\text { Không } \\
\text { làm }\end{array}$} & \multicolumn{2}{|c|}{$\begin{array}{l}\text { Làm không } \\
\text { đâyy đủ }\end{array}$} & \multicolumn{2}{|c|}{$\begin{array}{l}\text { Làm được } \\
\text { nhưng chưa } \\
\text { thành thạo }\end{array}$} & \multicolumn{2}{|c|}{$\begin{array}{l}\text { Làm tốt, } \\
\text { thành thạo }\end{array}$} \\
\hline & $\mathbf{n}$ & $\begin{array}{c}\text { Tỷ lệ } \\
\%\end{array}$ & $\mathbf{n}$ & $\begin{array}{c}\text { Tỷ lề } \\
\%\end{array}$ & $\mathbf{n}$ & $\begin{array}{c}\text { Ty̆ lề } \\
\%\end{array}$ & $\mathbf{n}$ & $\begin{array}{c}\text { Tỷ lệ } \\
\text { \% }\end{array}$ \\
\hline Môi trường giao tiếp & 0 & 0 & 0 & 0 & 2 & 7.7 & 24 & 92.3 \\
\hline $\begin{array}{l}\text { Quần áo, trang phục, đeo biển } \\
\text { tên, chức danh }\end{array}$ & 1 & 3.8 & 0 & 0 & & 0 & 25 & 96.2 \\
\hline Các phụ kiện đi kèm & 1 & 3.8 & 0 & 0 & 3 & 11.5 & 22 & 84.6 \\
\hline
\end{tabular}


VIETNAM MEDICAL JOURNAL N01 - MARCH - 2021

\begin{tabular}{|c|c|c|c|c|c|c|c|c|}
\hline $\begin{array}{c}\text { Cử chỉ, nét mặt, ánh mắt khi tiếp } \\
\text { xúc với người bệnh phù hợp }\end{array}$ & 1 & 3.8 & 1 & 3.8 & 3 & 11.5 & 21 & 80.8 \\
\hline $\begin{array}{c}\text { Sữ dụng tữ tượng thanh (nếu cần } \\
\text { phù hợp với hoàn cảnh giao tiếp }\end{array}$ & 2 & 7.7 & 1 & 3.8 & 4 & 15.4 & 19 & 73.1 \\
\hline $\begin{array}{c}\text { Tiếp xúc về mă̆t thế chất giữa } \\
\text { CBYT và người bệnh phù hợp }\end{array}$ & 2 & 7.7 & 0 & 0 & 1 & 3.8 & 23 & 88.5 \\
\hline $\begin{array}{c}\text { Giữ khoảng cách với CBYT và } \\
\text { người bệnh }\end{array}$ & 1 & 3.8 & & & 2 & 7.7 & 23 & 88.5 \\
\hline $\begin{array}{c}\text { Tư thế thăm khám/chăm sóc/thực } \\
\text { hiện thủ thuật }\end{array}$ & 0 & 0 & 0 & 0 & 2 & 7.7 & 24 & 92.3 \\
\hline $\begin{array}{c}\text { Thế hiện sự tôn troong, thân thiện } \\
\text { với NB }\end{array}$ & 0 & 0 & 0 & 0 & 3 & 11.5 & 23 & 88.5 \\
\hline $\begin{array}{c}\text { Kết hợp hài hòa ngôn ngữ không } \\
\text { lời và có lời }\end{array}$ & 0 & 0 & 0 & 0 & 2 & 7.7 & 24 & 92.3 \\
\hline
\end{tabular}

Nhận xét: Kết quả cho thấy kỹ năng giao tiếp không lời của kỹ thuật viên chủ yếu là làm tốt và thành thạo $(73,1-96,2 \%)$. Trong đó có $96.2 \%$ kỹ thuật viên có quần áo trang phục, đeo biển tên, chức danh đây đủ

Bảng 3.9: Tổng hợp kỹ năng giao tiếp, ứng xử của kỹ thuật viên

\begin{tabular}{|c|c|c|c|c|}
\hline \multirow{2}{*}{ Kũ̃ nắc độn } & \multicolumn{2}{|c|}{ Tốt } & \multicolumn{2}{c|}{ Chưa tốt } \\
\cline { 2 - 5 } & $\mathbf{n = 2 6}$ & Tỷ lệ \% & $\mathbf{n = 2 6}$ & Tỷ lệ \% \\
\hline Kỹ năng nói và lắng nghe & 26 & 100 & 0 & 0 \\
\hline Kỹ năng đặt câu hỏi và phản hồi & 21 & 80.8 & 5 & 19.2 \\
\hline Kỹ năng giao tiếp không lời & 25 & 96.2 & 1 & 3.8 \\
\hline Tổng hợp kỹ năng & $\mathbf{2 1}$ & $\mathbf{8 0 . 8}$ & $\mathbf{5}$ & $\mathbf{1 9 . 2}$ \\
\hline
\end{tabular}

Nhận xét: Qua bảng cho thấy kỹ năng nói và lắng nghe; kỹ năng giao tiếp không lời của kỹ thuật viên tỷ lệ tốt chiếm $100 \%$ và $96.2 \%$. Bên cạnh đó, kỹ năng đặt câu hỏi và phản hồi còn $19.2 \%$ là chưa tốt.

\section{BÀN LUẬN}

4.1. Kỹ năng nói và lắng nghe. Giao tiếp không chỉ đơn giản là biết cách nói. Giao tiếp tốt đòi hỏi cả 2 kỹ năng: nói và lắng nghe. Lắng nghe và biết cách lắng nghe sẽ giúp cán bộ y tế có thêm lợi thế và giành thêm thiện cảm của đồng nghiệp, cấp trên, người bệnh và người nhà người bệnh. Hơn nữa, biết lắng nghe - điều này có vẻ đởn giản nhưng không phải ai cũng có thể làm được vì vậy mỗi người trong chúng ta phải rèn luyện cho mình cách lắng nghe người khác, lắng nghe người khác cũng là một cách để nâng cao giá trị của mình. Người ta thường nói" Nói là bạc, im lặng là vàng".

Qua quan sát 26 kỹ thuật viên đang làm việc tại Bệnh viện Trường Đại học Kỹ thuật $Y$ tế Hải Dương cho thấy kỹ năng nói và lắng nghe đều đạt ở mức độ làm tốt và thành thạo. Tiêu chí chào và hỏi tển người bệnh, giới thiệu tên $\mathrm{CBYT}$, thể hiên sự tôn trong, thân thiên với NB kỹ thuất viên làm được nhưng chưa thành thạo chiếm $96.2 \%$, làm tốt, thành thạo chiếm $3.8 \%$ và kết hợp sử dụng ngôn ngữ không lời phù hợp, chào và cảm ơn người bệnh khi kêt thúc kỹ thuật viên làm được nhưng chưa thành thạo chiếm 92.3\%; làm tốt, thành thạo chiếm $7,7 \%$. Tuy nhiên, cán bộ y tế chưa có thói quen giới thiệu tên mình khi giao tiếp với người bệnh và cám ơn người bệnh đã đến khám taii bênh viên.

4.2. Kỹ năng đặt câu hỏi và phản hồi. Kỹ năng đặt câu hỏi trong giao tiếp là không khó, tuy nghiên đặt câu hỏi như thế nào cho hiệu quả là môt vấn đề khác. Và luôn luôn trong tư duy của người cán bộ y tế nên chú ý mình đang hỏi về vấn đề gì? Sử dụng câu hỏi đóng hay câu hỏi mở? Khi đă̆t câu hỏi bắt buộc phải hỏi có trọng tâm, sau đó là những câu cần hỏi có liên quan, chú ý các câu nên hỏi là những câu mang tính chất tìm hiểu, gợi mở vấn đề. Đồng thời không đặt những câu hỏi áp đặt. Hãy hỏi những câu hỏi ngắn gọn, cụ thể vào vấn đề, tốt nhất mỗi một vấn đề là một câu hỏi. Một điều quan trọng nữa là đừng ngắt lời khi người bệnh đang nói, có thái độ tôn trọng người bệnh khi người bệnh nói.

Kỹ năng đặt câu hỏi và phản hồi của kỹ thuật viên phần lớn làm được và làm tốt. Tuy nhiên, theo quan sát vẫn còn $11.5 \%$ kỹ thuật viên không tóm tắt lại những thông tin mà người bệnh vừa cung cấp, $15.4 \%$ kỹ thuật viên đưa ra ý kiến của mình.

4.3. Kỹ năng giao tiếp không lời. Ngôn ngữ dùng để biểu lộ suy nghĩ, ý định hoặc trạng 
thái của mỗi người và cũng còn có thể để che giấu, đánh lạc hướng người khác. Vì ngôn ngữ gắn liền với ý thức, nó được sử dụng một cách có chủ định của ý thức. Ngoài ra, có một loại "ngôn ngữ" khác ít hoặc không gắn liền với ý thức, nó có thể được biểu lộ một cách tự động, máy móc mà người khác chưa chắc đã hiểu ra. Đó là ngôn ngữ của cơ thể, được thể hiện bằng cử chỉ, điệu bộ, nét mặt... trong quá trình giao tiếp hay đó chính là giao tiếp không lời.

Qua quan sát cho thây kỹ năng giao tiếp không lời của kỹ thuật viên là làm được và thành thạo. Trong đó có $96.2 \%$ kỹ thuật viên có quần áo trang phục, đeo biển tên, chức danh đầy đủ

\section{KẾT LUÂN}

- Kỹ năng nói và lắng nghe của kỹ thuật viên được đánh giá chủ yếu là làm tốt và thành thạo $(80,8-92,3 \%)$.

- Kỹ năng đặt câu hỏi và phản hồi của kỹ thuật viên phần lớn làm tốt và thành thạo $(65,4-$ $92,3 \%)$.

- Kỹ năng giao tiếp không lời của kỹ thuật viên chủ yếu là làm tốt và thành thạo $(73,1-96,2 \%)$.

- Kỹ năng giao tiếp, ứng xử của đội ngũ kỹ thuật viên đang làm việc tại bệnh viện Trường Đại học Kỹ thuật $Y$ tế Hải Dương là tốt chiếm tỷ lệ $80.8 \%$.

\section{TÀI LIẸU THAM KHẢO}

1. Andrew Thompson (2006) "thuyết hài lòng của người bệnh" báo cáo trong hội nghị lần thứ VII của nhóm Điều dưỡng thế giới về suy giảm miễn dịch tại Budapest - Hungary, tr 35 .

2. Bộ Y tế (2015) Tài liệu Hướng dẫn giao tiếp, ứng xử của cán bộ y tế

3. Đào Thi Vui và cộng sự (2004), "Báo cáo về thực trạng giao tiếp của Điều dưỡng tại Bệnh viện Nhi Trüng ương",18-21.

4. Nguyễn Thị Phương Hoa, Nguyễn Thị Hồng Nhung, Vũ Quang Thanh (2015), "Đánh giá thực trạng giao tiếp của điều dưỡng đối với người bệnh trong quá trình điêu trị tại bệnh viện quân y 110".

5. Ngố Thị Ngoãn và cộng sự (2002), "Kết quả nghiên cứu sự hài lòng của người bệnh tại các khoa khám bệnh của 5 Bệnh viện khu vực Hà nội và các tỉnh", Kỷ yếu các đề tài nghiên cứu tại Hội nghị khoa học Điêu dưỡng toàn quốc lần thứ İ, Hộ̉i Điều dưỡng Việt nam 20-22.

6. Nguyễn Thị Hạ và cộng sự (2007), Tăng cường biện pháp nâng cao kỹ nắng giao tiếp cho điều dưỡng tại các bệnh viện ngành y tế Bắc Giang, Hội nghị khoa học điều dưỡng toàn quốc lần thứ III, tr.31-39.

\section{KIẾN THỨC, THỰC HÀNH TỰ KHÁM VÚ CỦA PHỤ NỮ 18-60 TUỔI TẠI THÀnH PHỐ CẦN THO'}

\section{TÓM TẮT}

Đặt vấn đề: Phương pháp tự khám vú (TKV) được khuyến khích thực hiện để phát hiện sớm ưng thư vú giai đoạn sớm và làm giảm tỷ lệ tử vong do ung thư vú. Mục tiêu: Xác định tỷ lệ kiến thức, thực hành tốt về tư khám vú và yếu tố liển quan của phụ nữ 18-60 tuổi tại thành phố Cần Thớ năm 2020. Phương pháp: Nighiên cứu mô tả cắt ngang 286 phụ nữ 18-60 tuổi tại thành phố Cần Thơ từ tháng 5 đến tháng 9 năm 2020. Phỏng vấn trực tiếp kiến thức, thực hành tự khám vú và một số yểu tố liên quan. Xứ lý số liệu bẳng phần mềm SPSS 20.0. Kết quả: tỷ lế kiến thức và thực hành tốt về tự khám vú lần lượt là $22,0 \%$ và $18,2 \%$. Kiến thức tự khám vú tốt hơn ở phu nữ là công chức viên chức, học vấn từ trung học phổ thông trở lên, phụ nữ dưới 2 con và có tìm hiểu thông

\footnotetext{
${ }^{1}$ Trường Đại học Y dược Cần Thơ ²Bênh viện Phụ sản thành phố Cần Thơ Chịu trách nhiệm chính: Nguyễn Minh Phương Email: nmphuong@ctump.edu.vn Ngày nhận bài: 5.01 .2021 Ngày phản biện khoa học: 26.2.2021 Ngày duyệt bài: 5.3.2021
}

\section{Nguyễn Minh Phương ${ }^{1}$, Lê Thị Kim Định ${ }^{2}$}

tin về ung thư vú với $p<0,05$. Yếu tố liên quan đến thực hành tự khám vú gồm 2 yêu tố là tình trạng hôn nhần và kiến thức tự khám vú, trong đó, thực hành tốt ở nhóm sống độc thân và kiến thức tự khám vú tốt cao hơn nhóm còn lại 3,104 lần (KTC 95\% 1,2127,948 ) và 4,57 lần (KTC 95\% 2,039-10,243). Kết luân: Kiến thức và thức hành tư khám vú ở phu nữ 18-60 tuổi tại thành phố Cần Thơ khá thấp. Các yểu tố cần chú ý trong can thiệp tăng cường kiên thức, thực hành tự khám vú là học vấn thấp, thiểu tiếp cận thông tin về ung thư vú, phụ nữ sinh nhiêu con.

Từ khóa: Tự khám vú, sàng lọc ung thư vú, kiến thức thực hành

\section{SUMMARY \\ KNOWLEDGE, PRACTICE OF BREAST SELF- EXAMININATION AMONG WOMEN 18-60 YEARS IN CAN THO \\ Background: Breast self-examination is} recommended for early detection of breast cancer and to reduce mortality from breast cancer. Objectives: To determine the prevalence of good knowledge and practice for breast self-examination and related factors among women 18-60 year in Can Tho, 2020. Methods: A cross-sectional study was conducted on 